\title{
ANALYTICAL MODEL OF COMPOSITE FLOORS WITH STEEL FIBRE REINFORCED CONCRETE SLAB SUBJECTED TO FIRE
}

\author{
Vadims GOREMIKINS ${ }^{\mathrm{a}, \mathrm{b}}$, Jiří ŠEJNOHA ${ }^{\mathrm{c}}$, František WALD ${ }^{\mathrm{a}}$, Jan BEDNÁŘ ${ }^{\mathrm{a}}$ \\ aDepartment of Steel and Timber Structures, Czech Technical University in Prague, \\ Thákurova 7, CZ16629 Prague, Czech Republic \\ ${ }^{b}$ Institute of Structural Engineering and Reconstruction, Riga Technical University, \\ Azenes 16, LV1048 Riga, Latvia \\ ${ }^{c}$ Department of Mechanics, Czech Technical University in Prague, \\ Thákurova 7, CZ16629 Prague, Czech Republic
}

Received 16 Oct 2014; accepted 07 Nov 2014

\begin{abstract}
Under fire, membrane action plays an important role in the performance of slabs subjected to large deflections. In this paper, a new model is proposed based on a proper approximation of horizontal displacements for a simply supported composite slab. The novelty of the proposed approach consists in a special treatment of the system of shape functions for the "in-plane" displacements. Moreover, a load applied to the slab is divided into two components, so that one component is balanced by the membrane forces, while the second one is transmitted by the bending forces (including transfer of shear and moment). The deflection due to thermal elongations is replaced by the identical deflection caused by a fictitious load. Unknown parameters are calculated using the principle of virtual displacements. The effectiveness of the model is validated by the results obtained from experiments.
\end{abstract}

Keywords: approximation of horizontal displacements, membrane action, composite slab, steel beams.

\section{Introduction}

It has long been recognised that the load applied to the slab is transmitted partly by the flexural rigidity and partly by the membrane action of the slab (Timoshenko, Woinowsky-Krieger 1959). In case of small displacements, design models do not allow for taking into account membrane forces (Timoshenko, Woinowsky-Krieger 1959). But in case of large deflections, which are acceptable in fire, membrane action can considerably enhance its load-carrying capacity (Bailey 2001). This behaviour is possible only in case of using the ductile material. It was proved that steel fibre reinforced concrete is sufficiently ductile for creating the membrane action (Fike, Kodur 2011; Meskenas et al. 2014; Marciukaitis et al. 2011). Partial differential equations describing the behaviour of the slab in the case of large deflections were introduced by Föppl and von Kármán as early as in the 1910s. Since the 1950s the interest to the membrane actions of slabs had increased. After Cardington experiments in the mid of the 1990s (Bailey et al. 1999, 2000), two different approaches have been developed to address the membrane action of slabs at elevated temperatures. They may be classified as: (i) analytical approaches, and (ii) FEM based approaches. There is a variety of both sim- plified and advanced analytical models developed since then (see, e.g. Bailey 2001; Usmani et al. 2001; Li et al. 2007; Wang 1997; Vassart, Zhao 2011). These models are proposed namely for reinforced concrete. A number of FEM models based on geometrically and physically nonlinear approach using commercial software packages like ABAQUS with FEAST subroutines (Gillie et al. 2001) or ANSYS (Vassart, Zhao 2011; Kodur et al. 2013) have been introduced. Specialised software packages like Vulcan (Huang et al. 2003; Huang 2010), Safir (Franssen et al. 2002; Fike, Kodur 2011) or SlabFEM (Tesar 2008; Stadler, Mensinger 2014) have been developed to simulate composite slabs under elevated temperatures. When utilizing the FEM models, the slab is mostly modelled with layered shell elements. It is worth mentioning that just in Fike and Kodur (2011) the authors consider the use of steel fibre reinforced concrete to enhance the fire resistance of composite floor assemblies. The relevant thermal and mechanical properties of steel-fibre reinforced concrete for use in fire resistance calculations can be found in Lie and Kodur (1996) and Bednář et al. (2013).

Starting from the previous achievements in this field, the present paper proposes a new simplified model, which belongs to category (i). As an auxiliary tool for design-

Corresponding author: Vadims Goremikins

E-mail: goremikins@gmail.com 
ing composite floors with steel fibre reinforced concrete slabs exposed to fire, the model should be simple and sufficiently quick in predicting the reasonable distribution of membrane forces and displacements during a fire. The proposed model covers both geometric and material non-linearity. It properly reflects the effect of thermal elongations governing the vertical displacements of the slab, namely at the stage of heating. In this stage, correct approximations of displacements and forces as well as the fulfilment of boundary conditions play a decisive role. Approximations of displacements in case of clamped edges were proposed by Timoshenko in Timoshenko and Woinowsky-Krieger (1959). A new model of the slab with simply supported edges is the subject of this paper. The effect of fire on a ceiling slab is twofold. It gives the rise to thermal elongations in the middle surface and causes a distinct reduction of the material stiffness.

The authors do not strive to predict the overall behaviour of the slab. Especially we are not aimed at the final stage preceding its collapse. Therefore, the model does not analyse in detail such phenomena as cracking in tensile zones, transient creep strains as well as development of plastic strains for concrete in compression, since their description at elevated temperatures might be dubious. Instead, the material properties are captured by the temperature-dependant overall characteristics, the stressstrain relationships, obtained from the experiments. The complexity of material modelling leaps to the eyes when comparing the results published in Lie and Kodur (1996) and Bednár et al. (2013). Recall that the resulting curves differ significantly.

The performance of the model is validated against a set of experiments carried out by the research team at the Czech Technical University in Prague. This paper is part of the complex research program including both the experiments on the response of composite floor slabs subjected to fire (Bednáŕ et al. 2012, 2013) and numerical simulations.

\section{Development of a new model}

The model is based on the von Kármán theory of large deflections for plates and shallow shells. Displacements in the middle surface of the slab are crucial variables of the model. Unknown parameters are calculated using the principle of virtual displacements. A novelty value of the proposed model consists in a special selection of shape functions for the "in-plane" displacements $u$ and $v$. They are classified into two sets. The first one serves to aptly cover the linear parts of expressions for membrane forces and the second set is used to satisfy the static boundary conditions (zero normal and shear forces prescribed on the boundary).

\subsection{Basic ideas and assumptions of the model}

A load $p$ applied to the slab is divided into two yet unknown components $p_{1}$ and $p_{2}$, so that $p_{1}$ is balanced by the membrane forces and $p_{2}$ is balanced by the bending forces (Timoshenko, Woinowsky-Krieger 1959). The load $p_{1}$ (membrane) generates a vertical displacement $a_{01}$ at the centre of the slab which is identical to the vertical displacement $a_{02}$ caused by the load $p_{2}$ (bending).

The deflection $w_{0}$ at the slab's centre brought about by thermal elongations is replaced by the identical deflection caused by a fictitious load $p_{0}$, which is balanced by the membrane forces. Therefore, the large deflections of the slab affect only the membrane forces.

The underlying equation thus reads:

$$
p_{1}+p_{2}=p
$$

where: $p_{1}$ is part of the load balanced by the membrane forces, $p_{2}$ is part of the load balanced by the bending forces, and $p$ is the applied external load.

Consequently, the second basic equation assumes this form:

$$
a_{01}=a_{02}=a_{00}-w_{0}
$$

where: $a_{00}$ is the total vertical displacement at the centre of the slab, $w_{0}$ is the vertical displacement at the centre of the slab caused by a fictitious load $p_{0}$ (thermal effect), $a_{01}$ is the vertical displacement caused by $p_{1}$ (membrane), and $a_{02}$ is the vertical displacement caused by $p_{2}$ (bending).

The slab in question is perceived to be simply supported (Fig. 1). This assumption seems reasonable for common slabs subjected to a high temperature as the connections gradually lose their stiffness due to cracks arising in continuous slabs above the supports and the slab subsequently becomes discontinuous.

A common secant modulus of elasticity is adopted for the whole thickness of the slab (defined in Section 2, Fig. 3). Geometric characteristics of the structure were calculated by stratifying it into layers and reducing the width of layers with respect to the modulus of elasticity. This modulus is dependent on temperature. Iterations were used to obtain a proper value of the modulus for each temperature depending on the current mechanical strain attained in each layer.

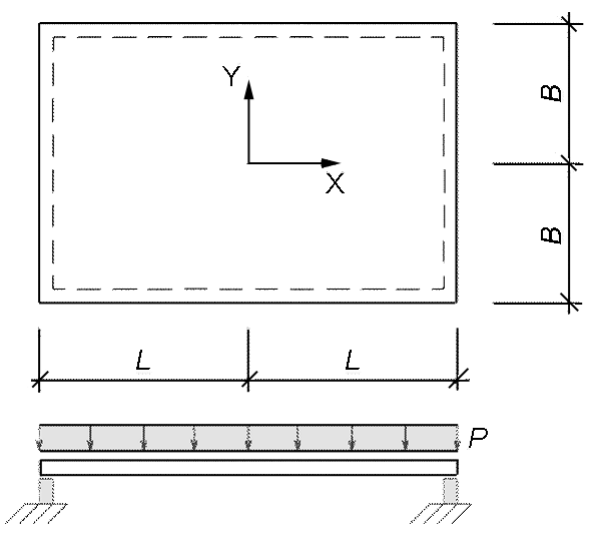

Fig. 1. Design scheme of slab with simply supported edges 


\subsection{Approximations of vertical displacements}

The vertical displacements of the middle surface of the slab caused by the membrane forces (loads $p_{1}$ and $p_{0}$ ) are approximated as:

$$
w=a_{00}\left(1-\frac{x^{2}}{L^{2}}\right)\left(1-\frac{y^{2}}{B^{2}}\right),
$$

where: $L$ and $B$ are the half of the length and the half of the width of the slab, respectively (see Fig. 1).

The vertical displacements of the middle surface of the slab caused by bending forces (load $\left.p_{2}\right)$ are approximated as:

$$
w_{2}=a_{02}\left(1-\frac{6}{5} \frac{x^{2}}{L^{2}}+\frac{1}{5} \frac{x^{4}}{L^{4}}\right)\left(1-\frac{6}{5} \frac{y^{2}}{B^{2}}+\frac{1}{5} \frac{y^{4}}{B^{4}}\right) .
$$

The vertical displacements of the middle surface of the slab caused by fictitious membrane forces (fictitious load $p_{0}$ ) are approximated as:

$$
w_{1}=w_{0}\left(1-\frac{x^{2}}{L^{2}}\right)\left(1-\frac{y^{2}}{B^{2}}\right) .
$$

The vertical displacement at the centre of the slab $w_{0}$, induced by thermal expansion, is evaluated by means of this simplified formula:

$$
w_{0}=B \sqrt{\frac{3}{2} \varepsilon_{\theta}},
$$

where: $\varepsilon_{\theta}$ is the overall thermal strain. The overall thermal strain, $\varepsilon_{\theta}$, of the homogenized cross-section is calculated as the weighted average satisfying the compatibility conditions along the thickness of the slab:

$$
\varepsilon_{\theta}=\sum_{i=1}^{n}\left(\varepsilon_{\theta, i} \cdot E_{i}\right) / \sum_{i=1}^{n} E_{i}
$$

where: $\varepsilon_{\theta, i}$ is the thermal strain and $E_{i}$ is the modulus of elasticity of each layer, $n$-number of layers of stratified cross-section.

\subsection{Approximations of horizontal displacements}

In case of a simply supported slab the following boundary conditions for the membrane forces should be satisfied:

$$
\left.N_{x}\right|_{x=L}=0,\left.N_{y}\right|_{y=B}=0,\left.N_{x y}\right|_{x=L}=0 \text { and }\left.N_{x y}\right|_{y=B}=0 .
$$

The von Kármán strain-displacement equations written for the middle surface will be adopted as a stepping stone for the approximation of "in-plane" displacements $u$ and $v$ :

$$
\begin{aligned}
& \varepsilon_{x}=\frac{\partial u}{\partial x}+\frac{1}{2}\left(\frac{\partial w}{\partial x}\right)^{2} \\
& \varepsilon_{y}=\frac{\partial v}{\partial y}+\frac{1}{2}\left(\frac{\partial w}{\partial y}\right)^{2}
\end{aligned}
$$

$$
\gamma_{x y}=\frac{\partial u}{\partial y}+\frac{\partial v}{\partial x}+\frac{\partial w}{\partial x} \frac{\partial w}{\partial y}
$$

The membrane forces are functions of strains:

$$
\begin{gathered}
N_{x}=\frac{E A_{x}}{1-v^{2}}\left(\varepsilon_{x}+v \varepsilon_{y}\right) ; \\
N_{y}=\frac{E A_{y}}{1-v^{2}}\left(\varepsilon_{y}+v \varepsilon_{x}\right) ; \\
N_{x y}=\frac{E A_{x y}}{1-v^{2}} \frac{1-v}{2} \gamma_{x y},
\end{gathered}
$$

where: $E$ is the modulus of elasticity, $A_{x}, A_{y}$ and $A_{x y}$ are the cross-section areas of the slab per $1 \mathrm{~m}$ run at each direction (described in Section 2, Fig. 5) and $v$ is the Poisson ratio.

Substituting Eqns (8)-(10) to Eqns (11)-(13) yields:

$$
\begin{gathered}
N_{x}=\frac{E A_{x}}{1-v^{2}}\left(\frac{\partial u}{\partial x}+v \frac{\partial v}{\partial y}+\frac{1}{2}\left(\frac{\partial w}{\partial x}\right)^{2}+v \frac{1}{2}\left(\frac{\partial w}{\partial y}\right)^{2}\right) ; \\
N_{y}=\frac{E A_{y}}{1-v^{2}}\left(\frac{\partial v}{\partial y}+v \frac{\partial u}{\partial x}+\frac{1}{2}\left(\frac{\partial w}{\partial y}\right)^{2}+v \frac{1}{2}\left(\frac{\partial w}{\partial x}\right)^{2}\right) \\
N_{x y}=\frac{E A_{x y}}{1-v^{2}} \frac{1-v}{2}\left(\frac{\partial v}{\partial x}+\frac{\partial u}{\partial y}+\frac{\partial w}{\partial x} \frac{\partial w}{\partial y}\right) .
\end{gathered}
$$

The linear parts of Eqns (14) and (15), i.e. expressions $\frac{\partial u}{\partial x}+v \frac{\partial v}{\partial y}$ and $\frac{\partial v}{\partial y}+v \frac{\partial u}{\partial x}$, will be approximated as follows:

$$
\begin{aligned}
& \frac{\partial u}{\partial x}+v \frac{\partial v}{\partial y}=\left(1-\frac{x^{2}}{L^{2}}\right)\left(b_{00}+b_{01} \frac{x^{2}}{L^{2}}+b_{02} \frac{y^{2}}{B^{2}}+\right. \\
& \left.b_{03} \frac{y^{4}}{B^{4}}\right)+v\left(1-\frac{x^{2}}{L^{2}}\right)\left(\frac{c_{03} y^{2} x^{2}}{L^{2} B^{2}}\right)+g_{1}(y) ; \\
& \frac{\partial v}{\partial y}+v \frac{\partial u}{\partial x}=\left(1-\frac{y^{2}}{B^{2}}\right)\left(c_{00}+c_{01} \frac{y^{2}}{B^{2}}+c_{02} \frac{x^{2}}{L^{2}}+\right. \\
& \left.c_{03} \frac{x^{4}}{L^{4}}\right)+v\left(1-\frac{y^{2}}{B^{2}}\right)\left(\frac{b_{03} y^{2} x^{2}}{L^{2} B^{2}}\right)+g_{2}(x),
\end{aligned}
$$

where: $b_{00}, b_{01}, b_{02}, b_{03}, c_{00}, c_{01}, c_{02}$ and $c_{03}$ are to be treated as still unknown parameters.

Functions $g_{1}(y)$ and $g_{2}(x)$ were introduced to satisfy boundary conditions $\left.N_{x}\right|_{x=L}=0$ and $\left.N_{y}\right|_{y=B}=0$. Substituting Eqns (17), (18) and (3) to Eqns (14) and (15) and setting $x=L$ for $N_{x}$ and $\mathrm{y}=\mathrm{B}$ for $N_{y}$ gives: 


$$
\begin{aligned}
& g_{1}(y)=\frac{2 a_{00}^{2}\left(1-\frac{y^{2}}{B^{2}}\right)^{2}}{L^{2}} ; \\
& g_{2}(x)=\frac{2 a_{00}{ }^{2}\left(1-\frac{x^{2}}{L^{2}}\right)^{2}}{B^{2}}
\end{aligned}
$$

Solving differential Eqns (17) and (18) results in the searched expressions for the horizontal displacements $u$ and $v$ :

$$
\begin{aligned}
u= & \frac{x}{15 B^{4} L^{4}\left(v^{2}-1\right)}\left[B ^ { 4 } \left(3 b_{01} x^{4}-5 b_{01} L^{2} x^{2}+\right.\right. \\
& 5 b_{00} L^{2}\left(x^{2}-3 L^{2}\right)+15 c_{00} L^{4} v+5 c_{02} L^{2} x^{2} v+ \\
& \left.3 c_{03} x^{4} v\right)+2 a_{00}^{2}\left(v \cdot 15 L^{2}\left(B^{2}-y^{2}\right)^{2}+\right. \\
& \left.B^{2}\left(10 L^{2} x^{2}-15 L^{4}-3 x^{4}\right)\right)-5 B^{2} L^{2} y^{2}\left(b _ { 0 2 } \left(3 L^{2}-\right.\right. \\
& \left.\left.x^{2}\right)+v\left(3 L^{2}\left(c_{00}-c_{01}\right)+x^{2}\left(c_{02}+c_{03}-b_{03} v\right)\right)\right)- \\
& \left.5 L^{2} y^{4}\left(3 c_{01} L^{2} v+b_{03}\left(3 L^{2}+x^{2}\left(v^{2}-1\right)\right)\right)\right]+C_{1}(y) ; \\
v= & \frac{y}{15 B^{4} L^{4}\left(v^{2}-1\right)}\left[3 L^{4} y^{4}\left(c_{01}+v b_{03}\right)+\right. \\
& 15 B^{4}\left(v\left(L^{2}-x^{2}\right)\left(b_{00} L^{2}+b_{01} x^{2}\right)-c_{00} L^{4}-\right. \\
& \left.c_{02} L^{2} x^{2}-c_{03} x^{4}\right)+2 a_{00}{ }^{2}\left(15 B^{2}\left(L^{2}-x^{2}\right)^{2}+\right. \\
& \left.v L^{2}\left(-15 B^{4}+10 B^{2} y^{2}-3 y^{4}\right)\right)+5 B^{2} y^{2}\left(c_{00} L^{4}-\right. \\
& c_{01} L^{4}+c_{02} L^{2} x^{2}+c_{03} x^{4}+v L^{2}\left(b_{02} L^{2}-\right. \\
& \left.\left.\left.\left(b_{02}+b_{03}\right) x^{2}\right)+v^{2} c_{03} x^{2}\left(L^{2}-x^{2}\right)\right)\right]+C_{2}(x) .
\end{aligned}
$$

Since Eqns (21) and (22) have also to obey the symmetry boundary conditions, i.e. $\left.u\right|_{x=0}=0$ and $\left.v\right|_{y=0}=0$, functions $C_{1}(y)$ and $C_{2}(\mathrm{x})$ must be equal to zero. To satisfy the boundary conditions for shear forces $\left(\left.N_{x y}\right|_{x=L}=0\right.$ and $\left.\left.N_{x y}\right|_{y=B}=0\right)$, as well as the symmetry conditions $\left(\left.N_{x y}\right|_{x=0}=0\right.$ and $\left.\left.\quad N_{x y}\right|_{y=0}=0\right)$, the expression for $\frac{\partial u}{\partial y}+\frac{\partial v}{\partial x}$ is presumed in the form:

$$
\begin{aligned}
& \frac{\partial u}{\partial y}+\frac{\partial v}{\partial x}=d_{00}\left(\frac{x}{L}-\frac{x^{3}}{L^{3}}\right)\left(\frac{y}{B}-\frac{y^{3}}{B^{3}}\right)= \\
& \frac{d_{00} x y}{B L}-\frac{d_{00} x^{3} y}{B L^{3}}-\frac{d_{00} x y^{3}}{B^{3} L}+\frac{d_{00} x^{3} y^{3}}{B^{3} L^{3}}
\end{aligned}
$$

where $d_{00}$ is the unknown parameter.

Recall that the nonlinear part of Eqn (16) satisfies both boundary conditions a priori. By differentiating Eqns (21) and (22) we obtain:

$$
\begin{aligned}
& \frac{\partial u}{\partial y}+\frac{\partial v}{\partial x}=\frac{-2 x y}{B^{2} L^{2}\left(v^{2}-1\right)}\left(8 a_{00}^{2}+B^{2}\left(c_{02}+b_{00} v-b_{01} v\right)+\right. \\
& \left.L^{2}\left(b_{02}+c_{00} v-c_{01} v\right)\right)+\frac{2 x^{3} y}{3 B^{2} L^{4}\left(v^{2}-1\right)}\left(12 a_{00}{ }^{2}-\right. \\
& \left.6 B^{2}\left(c_{03}+b_{01} v\right)+L^{2}\left(b_{02}+v\left(-c_{02}-c_{03}+b_{03} v\right)\right)\right)+ \\
& \frac{2 x y^{3}}{3 B^{4} L^{2}\left(v^{2}-1\right)}\left(12 a_{00}^{2}-6 L^{2}\left(b_{03}+c_{01} v\right)+\right. \\
& \left.B^{2}\left(c_{02}+v\left(-b_{02}-b_{03}+c_{03} v\right)\right)\right)-\frac{4\left(B^{2} c_{03}+b_{03} L^{2}\right)}{3 B^{4} L^{4}} x^{3} y^{3} .
\end{aligned}
$$

The compatibility condition requires that the shear strains calculated from Eqns (23) and (24) be identical. This yields a system of algebraic equations:

$$
\left\{\begin{array}{c}
d_{00}=-\frac{2\left(8 a_{00}{ }^{2}+B^{2}\left(c_{02}+b_{00} v-b_{01} v\right)\right)}{B L\left(v^{2}-1\right)}- \\
\frac{2 L^{2}\left(b_{02}+c_{00} v-c_{01} v\right)}{B L\left(v^{2}-1\right)} \\
d_{00}=-\frac{2\left(12 a_{00}{ }^{2}-6 B^{2}\left(c_{03}+b_{01} v\right)\right)}{3 B L\left(v^{2}-1\right)}- \\
\frac{2 L^{2}\left(b_{02}+v\left(-c_{02}-c_{03}+b_{03} v\right)\right)}{3 B L\left(v^{2}-1\right)} \\
d_{00}=-\frac{2\left(12 a_{00}{ }^{2}-6 L^{2}\left(b_{03}+c_{01} v\right)\right)}{3 B L\left(v^{2}-1\right)}- \\
\frac{2 B^{2}\left(c_{02}+v\left(-b_{02}-b_{03}+c_{03} v\right)\right)}{3 B L\left(v^{2}-1\right)} \\
d_{00}=-\frac{4\left(B^{2} c_{03}+b_{03} L^{2}\right)}{3 B L}
\end{array}\right.
$$

By solving them we eliminate parameters $b_{00}, b_{01}$, $b_{02}, b_{03}$.

Finally, inserting these parameters into Eqns (21) and (22) we arrive at final expressions for displacements $u$ and $v$.

\subsection{Determination of still unknown parameters}

The remaining unknown parameters $a_{00}, c_{00}, c_{01}, c_{02}, c_{03}$ and $d_{00}$ are to be found using the principle of virtual displacements:

$$
\delta V-\delta \iint(p \cdot w) d x d y=0 .
$$

The strain energy of membrane forces will be evaluated by: 


$$
V_{1}=\frac{1}{2} \iint\left(N_{x} \varepsilon_{x}+N_{y} \varepsilon_{y}+N_{x y} \gamma_{x y}\right) d x d y
$$

Analogically, the strain energy of bending forces will be calculated from:

$$
V_{2}=\frac{1}{2} \iint\left(M_{x} \frac{\partial^{2} w}{\partial x^{2}}+M_{y} \frac{\partial^{2} w}{\partial y^{2}}+2 M_{x y} \frac{\partial^{2} w}{\partial x \partial y}\right) d x d y,
$$

where $I_{x}, I_{y}$ and $I_{x y}$ are the cross-section moments of inertia of the slab per $1 \mathrm{~m}$ run at each direction (described in Section 2, Fig. 5).

Considering just moderate strains due to bending and torsional effects, the bending moments in Eqn (28) have already been expressed by the following formulae:

$$
\begin{gathered}
M_{x}=-\frac{E \cdot I_{x}}{1-v^{2}}\left(\frac{\partial^{2} w}{\partial x^{2}}+v \frac{\partial^{2} w}{\partial y^{2}}\right) ; \\
M_{y}=-\frac{E \cdot I_{y}}{1-v^{2}}\left(\frac{\partial^{2} w}{\partial y^{2}}+v \frac{\partial^{2} w}{\partial x^{2}}\right) ; \\
M_{x y}=\frac{E \cdot I_{x y}}{1-v^{2}}(1-v) \frac{\partial^{2} w}{\partial x \partial y} .
\end{gathered}
$$

Equation (26) must be satisfied for any variation of each of the unknown parameters. In such a way we obtain the system of six Eqns (32)-(37):

$$
f_{1}=\frac{\partial}{\partial a_{00}}\left(V_{1}-\iint\left(\left(p_{1}+p_{0}\right) \cdot w\right) d x d y\right)=0,
$$

and

$$
\begin{aligned}
& f_{2}=\frac{\partial V_{1}}{\partial c_{00}}=0, f_{3}=\frac{\partial V_{1}}{\partial c_{01}}=0, f_{4}=\frac{\partial V_{1}}{\partial c_{02}}=0 \\
& f_{5}=\frac{\partial V_{1}}{\partial c_{03}}=0, f_{6}=\frac{\partial V_{1}}{\partial d_{00}}=0 .
\end{aligned}
$$

Assuming that bending moments are not to be dependent on the initial deflection induced by temperature, allows us to determine parameter $a_{02}$ which is proportional to $p_{2}$, see Eqns (38):

$$
\frac{\partial}{\partial a_{02}}\left(V_{2}-\iint\left(p_{2} \cdot w_{2}\right) d x d y\right)=0 .
$$

To obtain the fictitious load $p_{0}$ as a function of $w_{0}$, Eqns (32)-(37) can be used replacing $w$ by $w_{1}$ and $a_{00}$ by $w_{0}$.

Eqns (32)-(37) are linear in parameters $c_{00}, c_{01}, c_{02}$, $c_{03}, d_{00}$ and nonlinear in parameter $a_{00}$.

The calculation proceeds in these steps:

1. Determine $a_{02}$ using Eqn (38).

2. Determine $p_{0}$ as a function of $w_{0}$ from the system of Eqns (32)-(37) replacing $w$ by $w_{1}$ and $a_{00}$ by $w_{0}$.

3. Determine $c_{00}, c_{01}, c_{02}, c_{03}, d_{00}$ as a function of $a_{00}$ by solving the system of Eqns (33)-(37).
4. Determine $a_{00}$ by solving the system of equations:

$$
\left\{\begin{array}{l}
\frac{\partial}{\partial a_{00}}\left(V_{1}-\iint\left(\left(p_{1}+p_{0}\right) \cdot w\right) d x d y\right)=0 \\
p_{1}+p_{2}=p \\
a_{01}=a_{00}-w_{0}
\end{array} .\right.
$$

\section{Validation of the model}

The ribbed composite steel fibre reinforced concrete slab with steel beams displayed in Figure 2 was considered as an object of investigation. Experimental data of slab tests at elevated temperatures obtained at 21.10.2010 and 11.10.2011 in PAVUS laboratory in Veselí nad Lužnicí (Bednár et al. 2012, 2013) are used to validate the analytical model. The span and width of the structure is equal to 4.5 and $3.0 \mathrm{~m}$, respectively. The slab was loaded by the load equal to $1.8 \mathrm{kN} / \mathrm{m}^{2}$. The distance of the steel beams IPE100 is equal to $1 \mathrm{~m}$. The beams are connected to the slab using studs.

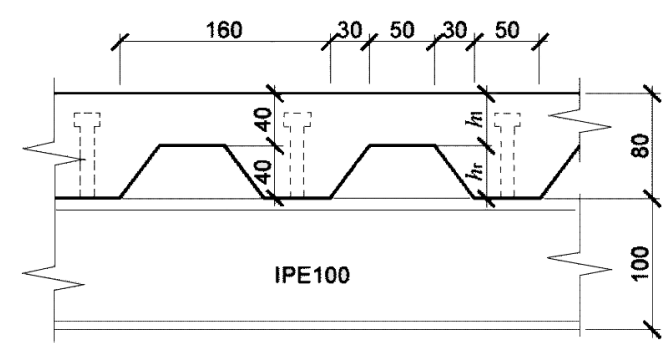

Fig. 2. Transversal cut of slab

The stress-strain curves of steel-fibre reinforced concrete used in the experiment at different temperatures are shown in Figure 3. Formulas for the stress-strain relationships of SFRC were obtained based on the experiments (Bednár et al. 2013) using the method presented in Gernay and Franssen (2011), by the first author as part of his $\mathrm{PhD}$ thesis and improved by the first author. The secant modulus of elasticity ( $E=\tan \alpha$, see Fig. 3 ) dependent on temperature was used in computational simulations.

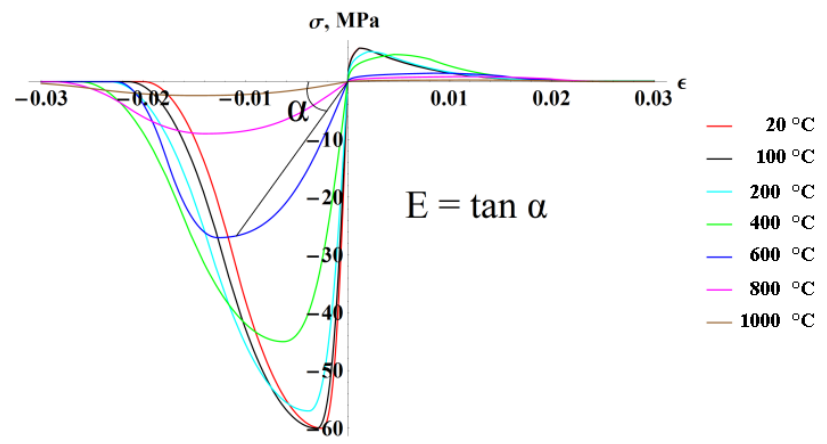

Fig. 3. Stress-strain curves of steel-fibre reinforced concrete at different temperatures and definition of secant modulus of elasticity $(E)$ 
Material characteristics of steel were applied according to EN 1993-1-2 (2005).

The nominal standard fire curve was used at the experiments. The experiment at 2011 was terminated before reaching the fire resistance after $126 \mathrm{~min}$ in order to follow the development of displacements in the course of cooling phase. A thermal analysis was carried out using the differential method of heat transfer (Incropera et al. 2006). The effective thickness of the slab for thermal analysis was taken as $h_{1}+h_{r} / 2$ (EN 1994-1-2 2005). Distribution of temperature through the thickness in time is shown in Figure 4. The temperature of steel beams and

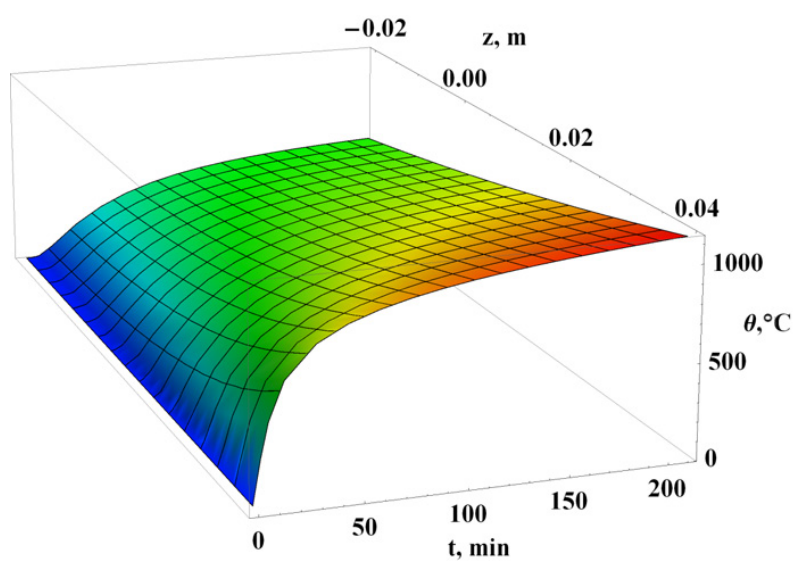

Fig. 4. Distribution of temperature through thickness of slab over time the remaining parts of the ribs was assumed to be equal to the temperature of the external layer of the calculated slab. The thermal characteristics of materials are used according to EN 1993-1-2 (2005) and EN 1992-1-2 (2004).

Geometric characteristics of the structure were calculated by stratifying the structure into layers and reducing the width of layers according to the current modulus of elasticity (Fig. 5). Rigid connection is assumed between the beams and the slab.

\section{Results and discussions}

A stress distribution in the middle surface is shown in Figures 6 and 7. In the centre region of the slab tensile stresses are observed, while in the vicinity of edges compressive stresses appear. This phenomenon confirms the theory of tensile membrane at the centre of the slab and compressive ring near the boundaries. Shear stress distribution is shown in Figure 8.

The evolution of horizontal displacements $u$ in the $x$-direction on one quarter of the slab is displayed in Figure 9. It is shown that the symmetry condition is satisfied. The utmost horizontal movements of individual points toward the centre of the slab appear at the corners of the slab. The evolution of membrane forces in the middle surface due to horizontal displacements $u$ and $v$ is shown in Figure 10.
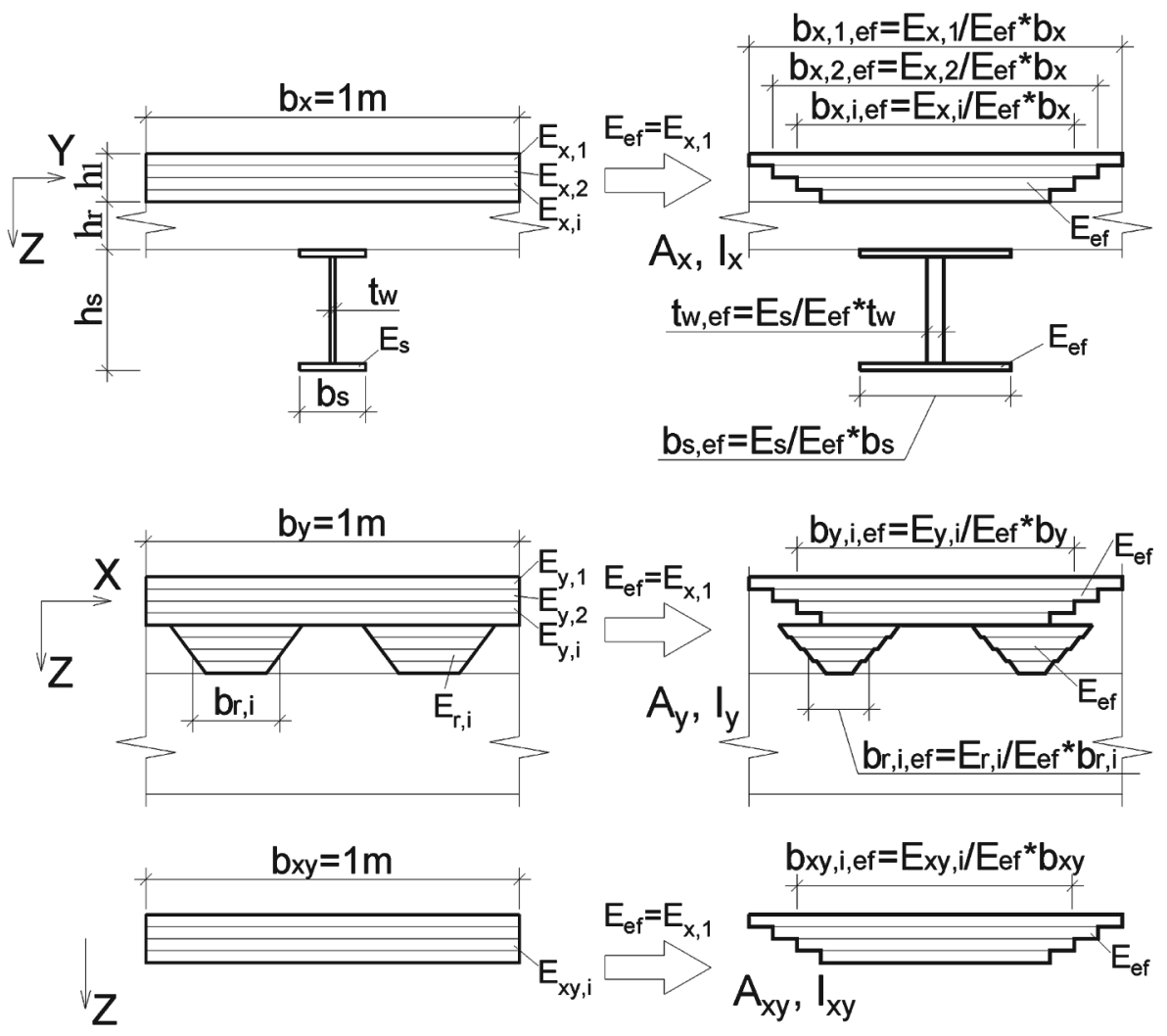

Fig. 5. Determination of effective cross-section of slab 


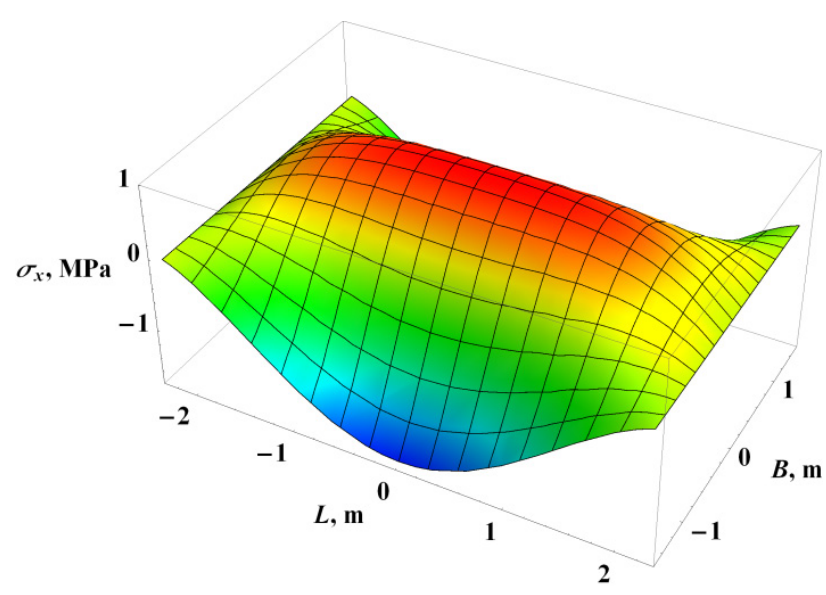

Fig. 6. Normal stress $\sigma x$ distribution in middle surface (time $120 \mathrm{~min}$ )

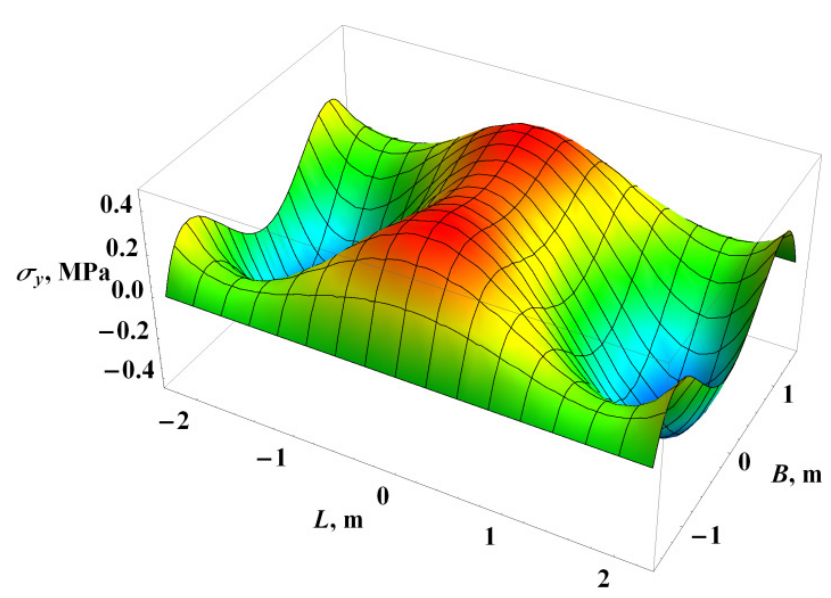

Fig. 7. Normal stress oy distribution in middle surface (time $120 \mathrm{~min}$ )

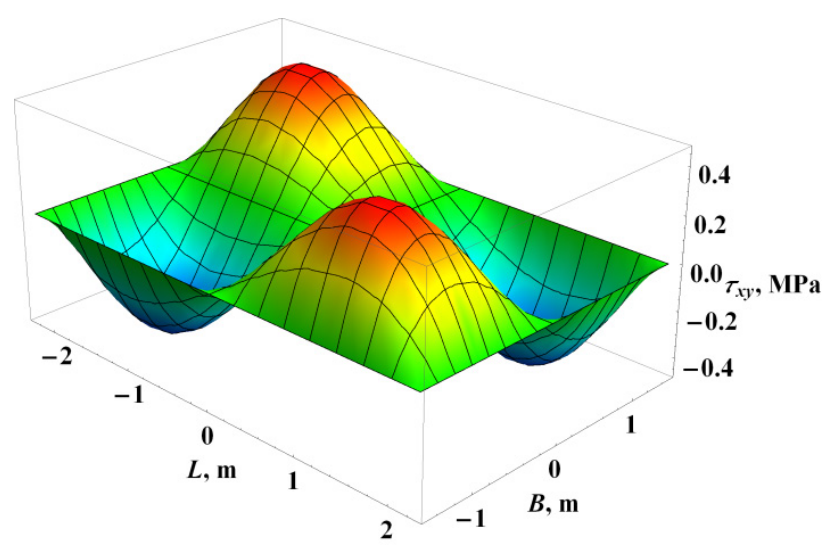

Fig. 8. Shear stress distribution in middle surface (time $120 \mathrm{~min}$ )

The evolution of the load taken by the membrane and by the bent slab, respectively, is shown in Figure 11. It is evident that at ambient temperature all the load is taken by the bending resistance of the slab, but increasing temperature causes the increase in deflections and after 60 minutes (in current experiment) the bending resistance of the slab becomes negligible.

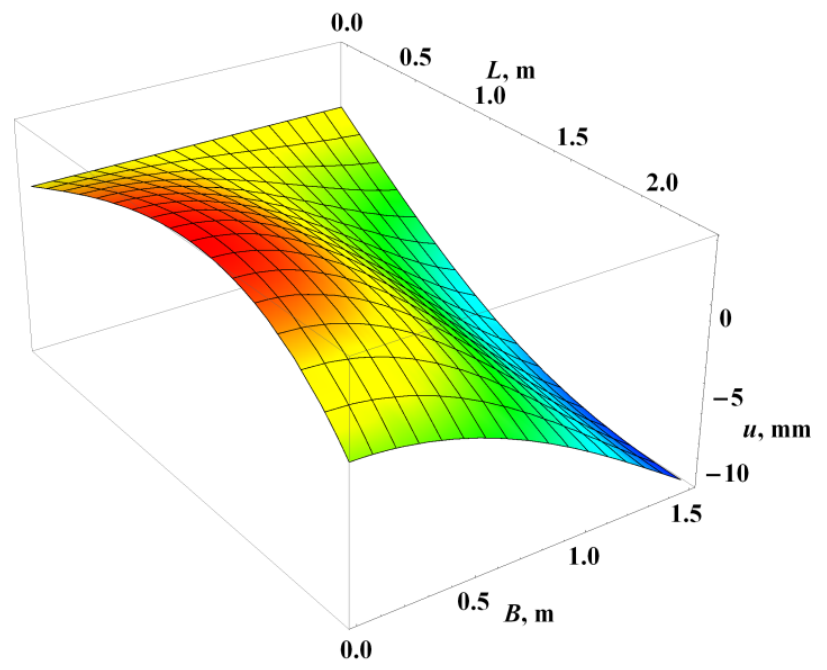

Fig. 9. Horizontal displacements $u$ in middle surface (time $120 \mathrm{~min}$ )

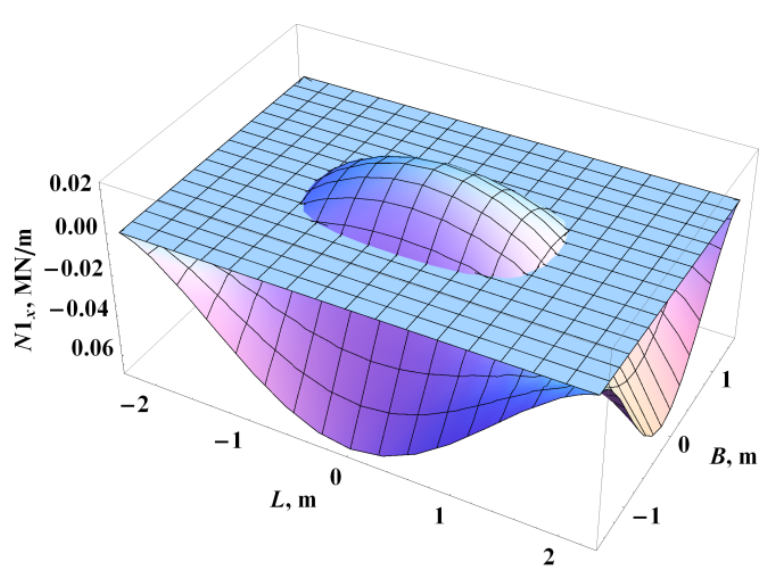

Fig. 10. Membrane forces N1x in middle surface subjected to horizontal displacements ( $u$ and $v$ ) only (time $120 \mathrm{~min}$ )

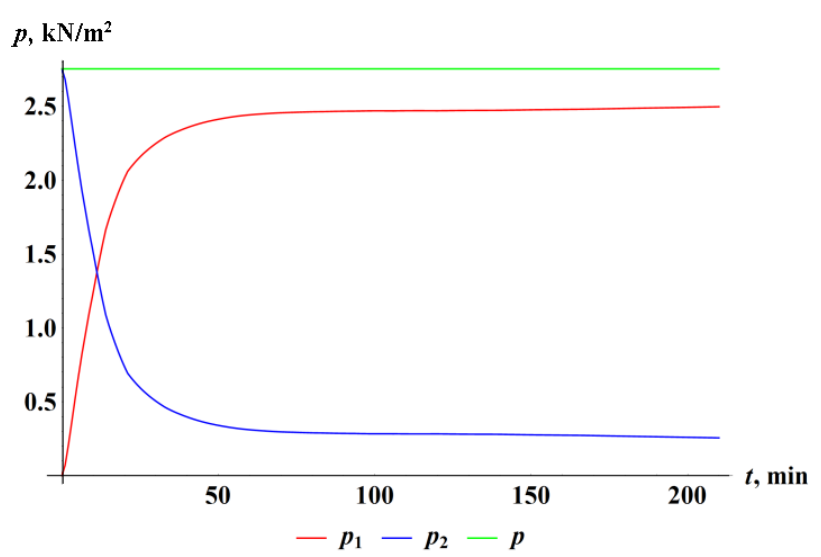

Fig. 11. Load distribution between bending and membrane resistance of slab; $p_{1}-$ load taken by membrane, $p_{2}-$ load taken by bending resistance, $p$ - applied load

The evolution of vertical displacements in time is shown in Figures 12 and 13. The thermal deflection represents the main component of total deflection. 


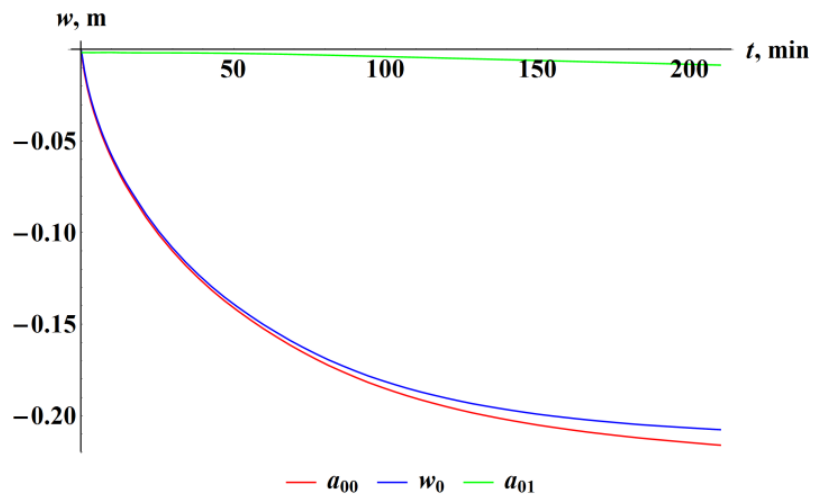

Fig. 12. Evolution of vertical displacement of central point in time; $a_{00}$ - total displacements, $w_{0}$ - displacements caused by temperature, $a_{01}$ - displacements caused by mechanical load

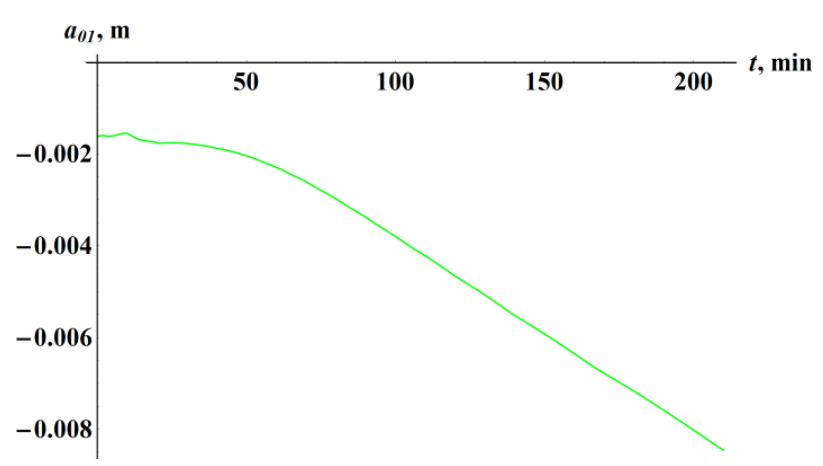

Fig. 13. Evolution of vertical displacement $a_{01}$ of central point caused by mechanical load in time

The comparison of deflections received from the experiments and by the model is shown in Figures 14 and 15. Slight fluctuations of displacements at the initial phase of experiment can be ascribed to the fact that boundaries at the beginning of the experiment do not perform as simply supported, but provide a certain torsional rigidity, which, in the course of time, becomes negligible. This process is rather difficult to describe analytically. This phenomenon is typical for both analytical and FEMbased models; and at the initial stage of heating predominates over the remaining effects of material modelling.

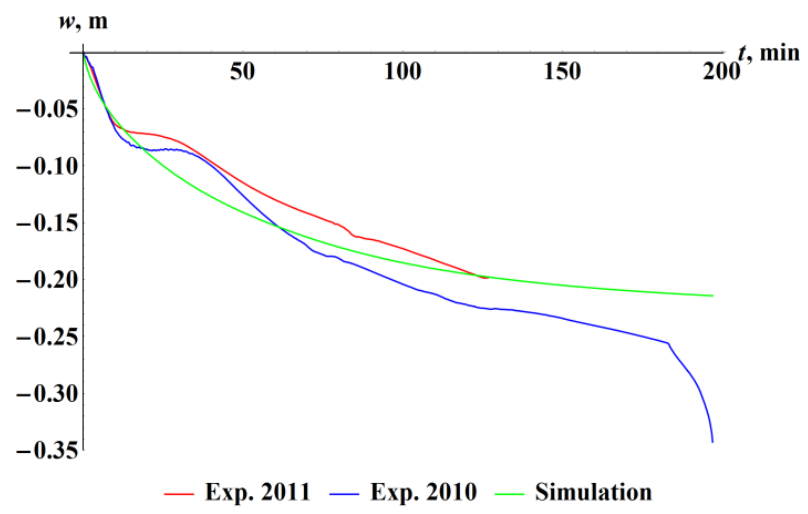

Fig. 14. Experimentally derived and analytically predicted deflections at centre of slab

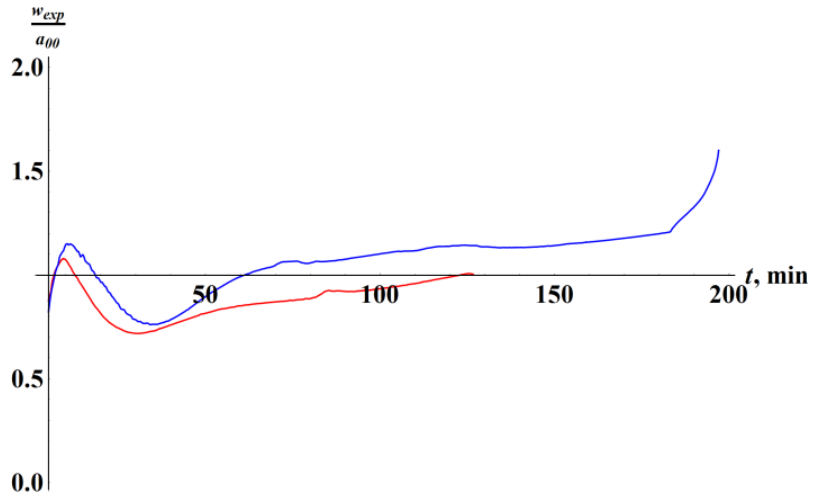

- Exp. 2011 - Exp. 2010

Fig. 15. Comparison of experimentally derived and analytically predicted deflections at centre of slab

The prediction of failure of structure could be performed by analysing the strains and defining limits. These results are under preparation and will be presented in a forthcoming journal paper.

\section{Conclusions}

The model with novel approximations of horizontal displacements, which satisfy the boundary conditions, allows predicting the overall performance of the slab. At the end of heating, the deflection caused by mechanical load exhibits not more than $4 \%$ from the total deflection. The model confirms the phenomena of appearance of a tension membrane at the centre of the slab and a compressive ring around the perimeter. The load transmitted by the bending resistance of the slab is less than $20 \%$ of the applied load after $30 \mathrm{~min}$ and is less than $12 \%$ of the applied load after $60 \mathrm{~min}$ according to the current experiment. The ratio of calculated to experimentally obtained deflections varies from 0.72 to 1.2 not considering the phase of the collapse of the structure.

\section{Acknowledgements}

The work presented in this paper is supported by the project "Support for the improvement of teams in R\&D and development of intersectoral mobility at the Czech Technical University in Prague" (No. CZ.1.07/2.3.00/30.0034).

This outcome has been also achieved with financial support of the Grant Agency of Czech Republic No. P105/10/21591.

Support for this work was also provided by the Riga Technical University through the Scientific Research Project Competition for Young Researchers No. ZP-2013/4.

\section{References}

Bailey, C. G. 2001. Membrane action of unrestrained lightly reinforced concrete slabs at large displacements, Engineering Structures 23(5): 470-483. http://dx.doi.org/10.1016/S0141-0296(00)00064-X

Bailey, C. G.; Lennon, T.; Moore, D. B. 1999. The behaviour of full-scale steel-framed buildings subjected to compartment fires, The Structural Engineer 77(8): 15-21. 
Bailey, C. G.; White, D. S.; Moore, D. B. 2000. The tensile membrane action of unrestrained composite slabs simulated under fire condition, Engineering Structures 22(12): 1583-1595. http://dx.doi.org/10.1016/S0141-0296(99)00110-8

Bednář, J.; Wald, F.; Vodička, J.; Kohoutková, A. 2012. Membrane action of composite fibre concrete slab in fire, Procedia Engineering 40: 498-503. http://dx.doi.org/10.1016/j.proeng.2012.07.132

Bednář, J.; Wald, F.; Vodička, J.; Kohoutková, A. 2013. Experiments on membrane action of composite floors with steel fibre reinforced concrete slab exposed to fire, Fire Safety Journal 59: 111-121. http://dx.doi.org/10.1016/j.firesaf.2013.04.008

EN 1992-1-2 2004. Eurocode 2: Design of concrete structures Part 1-2: General rules - Structural fire design. Brussels, 2004. 97 p.

EN 1993-1-2 2005. Eurocode 3: Design of steel structures Part 1-2: General rules - Structural fire design. Brussels, 2005. $78 \mathrm{p}$.

EN 1994-1-2 2005. Eurocode 4: Design of composite steel and concrete structures - Part 1-2: General rules - Structural fire design. Brussels, 2005. 109 p.

Fike, R.; Kodur, V. 2011. Enhancing the fire resistance of composite floor assemblies through the use of steel fiber reinforced concrete, Engineering Structures 33(10): 2870 2878. http://dx.doi.org/10.1016/j.engstruct.2011.06.011

Franssen, J. M.; Kodur, V. K. R.; Mason, J. 2002. Elements of theory for Safir: a computer program for analysis of structures submitted to the fire. University of Liege, Department Mécanique des Matériaux \& Structures, Liege. 34 p.

Gernay, T.; Franssen, J. M. 2011. Safir manual. Material properties. University of Liege, Liege. 39 p.

Gillie, M.; Usmani, A. S.; Rotter, J. M. 2001. A structural analysis of the first Cardington test, Journal of Constructional Steel Research 57: 581-01. http://dx.doi.org/10.1016/S0143-974X(01)00004-9

Huang, Z. 2010. The behaviour of reinforced concrete slabs in fire, Fire Safety Journal 45(5): 271-282. http://dx.doi.org/10.1016/j.firesaf.2010.05.001

Huang, Z.; Burgess, I. W.; Plank, R. J. 2003. Modeling membrane action of concrete slabs in composite buildings in fire. I: theoretical development, Journal of Structural Engineering 129(8): 1093-1102.

http://dx.doi.org/10.1061/(ASCE)0733-9445(2003)129:8(1093)
Incropera, F. P.; DeWitt, D. P.; Bergman, T. L.; Lavine, A. S. 2006. Fundamentals of heat and mass transfer. $6^{\text {th }}$ ed. John Wiley \& Sons. 1072 p.

Kodur, V. K. R.; Naser, M.; Pakala, P.; Varma, A. 2013. Modeling the response of composite beam-slab assemblies exposed to fire, Journal of Constructional Steel Research 80: 163-173. http://dx.doi.org/10.1016/j.jcsr.2012.09.005

Li, G. Q.; Guoa, S. X.; Zhou, H. S. 2007. Modelling of membrane action in floor slabs subjected to fire, Engineering Structures 29(6): 880-887.

http://dx.doi.org/10.1016/j.engstruct.2006.06.025

Lie, T. T.; Kodur, V. K. R. 1996. Thermal and mechanical properties of steel-fibre-reinforced concrete at elevated temperatures, Canadian Journal of Civil Engineering 23(4): 511-517. http://dx.doi.org/10.1139/196-055

Marciukaitis, G.; Šalna, R.; Jonaitis, B.; Valivonis, J. 2011. A model for strength and strain analysis of steel fiber reinforced concrete, Journal of Civil Engineering and Management 17(1): 137-145. http://dx.doi.org/10.3846/13923730.2011.561521

Meskenas, A.; Gribniak, V.; Kaklauskas, G.; Arnautov, A. K.; Rimkus, A. 2014. Simplified technique for constitutive analysis of SFRC, Journal of Civil Engineering and Management 20(3): 446-453. http://dx.doi.org/10.3846/13923 730.2014 .909882

Stadler, M.; Mensinger, M. 2014. Simplified finite element analyses for fire design of slabs including membrane action, Steel Construction 7(1): 1-7.

http://dx.doi.org/10.1002/stco.201310033

Tesar, C. N. 2008. Zum Tragverhalten von Verbunddeckensystemen im Brandfall. ETH Zürich, Diss. 189 p.

Timoshenko, S.; Woinowsky-Krieger, S. 1959. Theory of plates and shells. McGraw-Hill Book Company. 580 p.

Usmani, A. S.; Rotter, J. M.; Lamont, S.; Sanad A. M.; Gillie, M. 2001. Fundamental principles of structural behaviour under thermal effects, Fire Safety Journal 36(8): 745767. http://dx.doi.org/10.1016/S0379-7112(01)00037-6

Vassart, O.; Zhao, B. 2011. Fire resistance assessment of partially protected composite floors (FRACOF). Engineering background. ArcelorMittal \& CTICM. 128 p.

Wang, Y. C. 1997. Tensile membrane action and the fire resistance of steel framed buildings, in Proc. of the $5^{\text {th }}$ International Symposium on Fire Safety Science, 3-7 March 1997, Melbourne, Australia, 1117-1128. http://dx.doi.org/10.3801/iafss.fss.5-1117

Vadims GOREMIKINS. Dr Sc.Ing. Postdoctoral Researcher at Department of Steel and Timber Structures of Czech Technical University in Prague, Czech Republic and Leading Researcher at Institute of Structural Engineering and Reconstruction of Riga Technical University, Latvia. Author and co-author of 21 scientific publications. Research interests: structural fire design, composite structures, cable structures, suspension bridges.

Jiří ŠEJNOHA. Dr Sc. Prof. at Department of Mechanics of Czech Technical University in Prague, Czech Republic. Member of Scientific Board. Author and co-author of more than 250 scientific articles. Research interests: tunnel construction, masonry structures, numerical methods, composite structures.

František WALD. CSc. Prof. at Department of Steel and Timber Structures of Czech Technical University in Prague, Czech Republic. Member of Faculty Academic Senate, Member of Scientific Board. Author and co-author of more than 160 scientific and methodological publications. Research interests: steel structures, connection design, structural fire design, aluminium structures, sandwich panels.

Jan BEDNÁř. Ing. PhD student. Researcher at Department of Steel and Timber Structures of Czech Technical University in Prague, Czech Republic. Author of 2 scientific publications. Research interests: structural fire design, concrete structures. 